\title{
Bilateral Synchronous Mucoepidermoid Carcinoma of the Parotid Gland
}

\author{
Meltem Akpınar, Özlem Ünsal, Mahmut Çankaya, Fatih Tetik, Berna Uslu Coşkun
}

Department of Otorhinolaryngology Head and Neck Surgery, Sisli Hamidiye Etfal Training and Research Hospital, Istanbul, Turkey

\begin{abstract}
Mucoepidermoid carcinoma is the most common malignant tumor of the parotid; however, its synchronous occurrence in both of the parotid glands is extremely rare. Herein, we presented a case of 53-year-old man with bilateral synchronous mucoepidermoid carcinoma of the parotid gland treated with surgery.

The patient mainly complained of a painless mass in the left parotid gland. A mass located in the right parotid gland was incidentally detected by imaging. Based on cytopathology, left total parotidectomy was performed while preserving the facial nerve with ipsilateral neck dissection, and 5 weeks later, right superficial parotidectomy was performed. At the 3-year follow-up, there was no recurrence in the parotid regions and the neck.

A detailed examination for parotid masses is suggested for identifying possible occult synchronous tumors in the contralateral side or in other salivary glands. A close follow-up is also recommended for the risk of future occurrence of metachronous tumors. Keywords: mucoepidermoid carcinoma, parotid gland, bilateral, synchronous, salivary gland

Please cite this article as "Akpinar M., Unsal O., Cankaya M., Tetik F., Uslu Coskun B. Bilateral Synchronous Mucoepidermoid Carcinoma of the Parotid Gland. Med Bull Sisli Etfal Hosp 2018;52(2):145-148".
\end{abstract}

$\mathrm{M}$ ucoepidermoid carcinoma is the most common malignant tumor of the parotid gland. ${ }^{[1,2]}$ It usually occurs as a unilateral lesion and accounts for $30 \%$ of malignant salivary gland tumors. ${ }^{[2]}$ Bilateral mucoepidermoid carcinoma of the parotid gland is rarely encountered and may occur synchronously or metachronously..$^{[1,3-6]}$

In the present case, we report a patient with synchronous bilateral mucoepidermoid carcinoma of the parotid gland.

\section{Case Report}

A 53-year-old male patient was admitted to our clinic with a complaint of left preauricular painless swelling for 1 month. Physical examination revealed a $2 \times 3-\mathrm{cm}$, firm, semi-mobile and painless lesion localized to the left pre- auricular area. Neck ultrasonography (US) revealed a $29 \times 13 \times 31-\mathrm{mm}$, anechoic, thick-walled cystic lesion with peripheral vascularization and echogenicity extending to the cyst lumen in the left parotid gland. Additionally, in the right parotid gland, a thin-walled, anechoic $10 \times 7-\mathrm{mm}$, cystic lesion with indistinguishable boundaries was detected. Round, $12 \times 8-\mathrm{mm}$, hypoechogenic lymph nodes with indistinguishable central echogenic hilum were also detected sonographically on the left side of the neck at the level 2 region. Contrast-enhanced magnetic resonance imaging (MRI) revealed a lobulated, irregular mass $(32 \times 22 \mathrm{~mm})$ located in the anteroinferior segment of the superficial lobe of the left parotid gland, with areas of extensive central necrosis, septation, and peripheral wall enhancement and a pure cystic lesion lateral to the retromandibular vein in

Address for correspondence: Özlem Ünsal, MD. Department of Otorhinolaryngology Head and Neck Surgery, Sisli Hamidiye Etfal Training and Research Hospital, Istanbul, Turkey

Phone: +90 5326919993 E-mail: ozlemunsal@hotmail.com

Submitted Date: March 07, 2017 Accepted Date: April 17, 2017 Available Online Date: May 21, 2018

${ }^{\circ}$ Copyright 2018 by The Medical Bulletin of Sisli Etfal Hospital - Available online at www.sislietfaltip.org

This is an open access article under the CC BY-NC-ND license (http://creativecommons.org/licenses/by-nc/4.0/). 


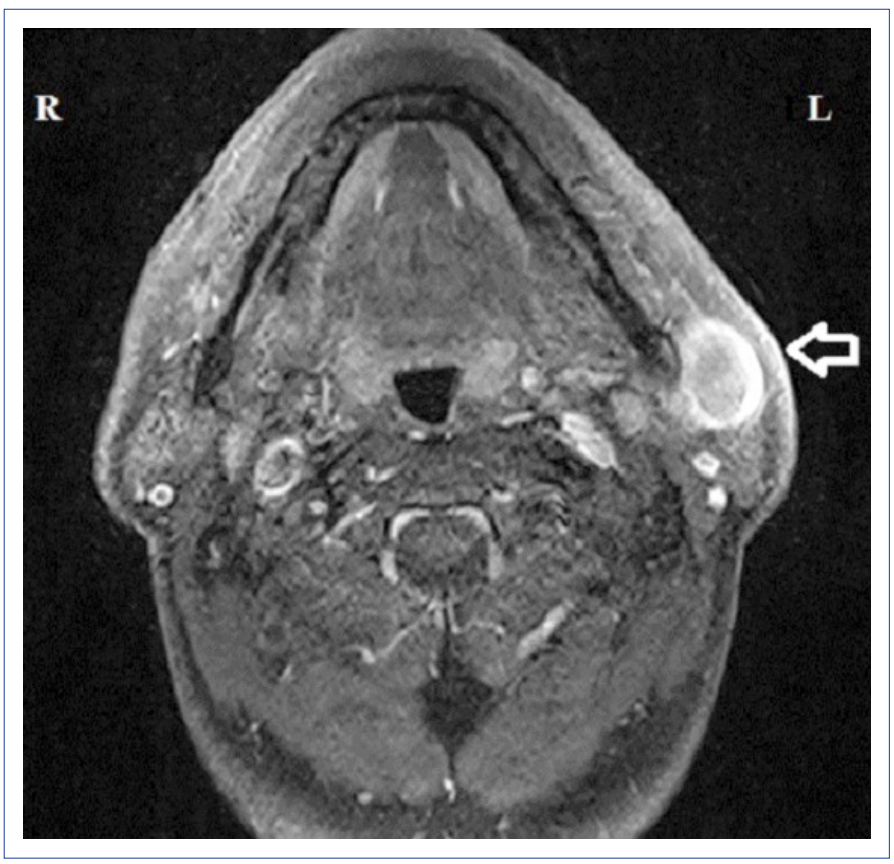

Figure 1. MRI of the left parotid mass.

the right parotid gland (Figs. 1, 2). The morphology of the upper jugular lymph nodes was reported as benign in MRI. Fine needle aspiration biopsy (FNAB) of the left parotid mass was reported as mucoepidermoid carcinoma. FNAB of the right parotid mass was reported as cytology with lymphocytes and epithelial and myoepithelial cells.

The patient was scheduled for staged left and right parotidectomy. On the first stage, left total parotidectomy was performed while preserving the facial nerve. The intraoperative frozen section confirmed mucoepidermoid carcinoma, and left neck dissection (levels 1, 2, 3, and 4) was also

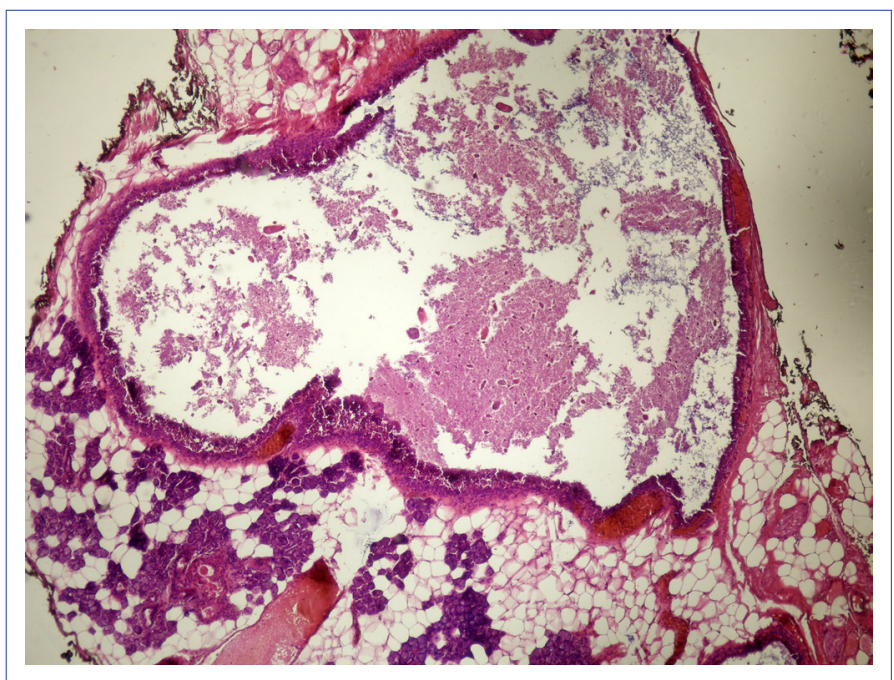

Figure 3. Histopathologic slide of intermediate-grade mucoepidermoid carcinoma of the left parotid gland (magnification, $\times 200$; hematoxylin-eosin stain).

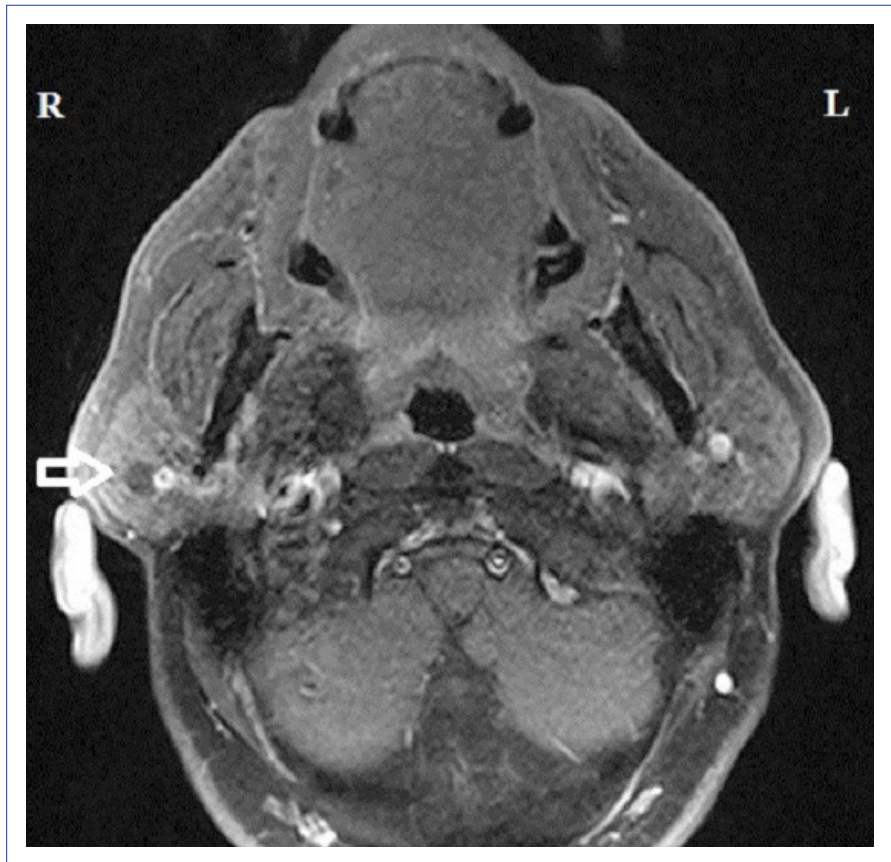

Figure 2. MRI of the right parotid mass.

performed. The facial nerve functions were normal postoperatively. Five weeks later, the right parotid mass was excised through superficial parotidectomy. The intraoperative frozen section of the lesion revealed low-grade mucoepidermoid carcinoma. Owing to the histological grade of the tumor, neck dissection was not performed. The right facial nerve functions were also intact postoperatively.

The final histopathology of left and right surgical specimens confirmed the frozen section findings and was reported as intermediate- and low-grade mucoepidermoid carcinomas, respectively (Figs. 3, 4). The pathology of the

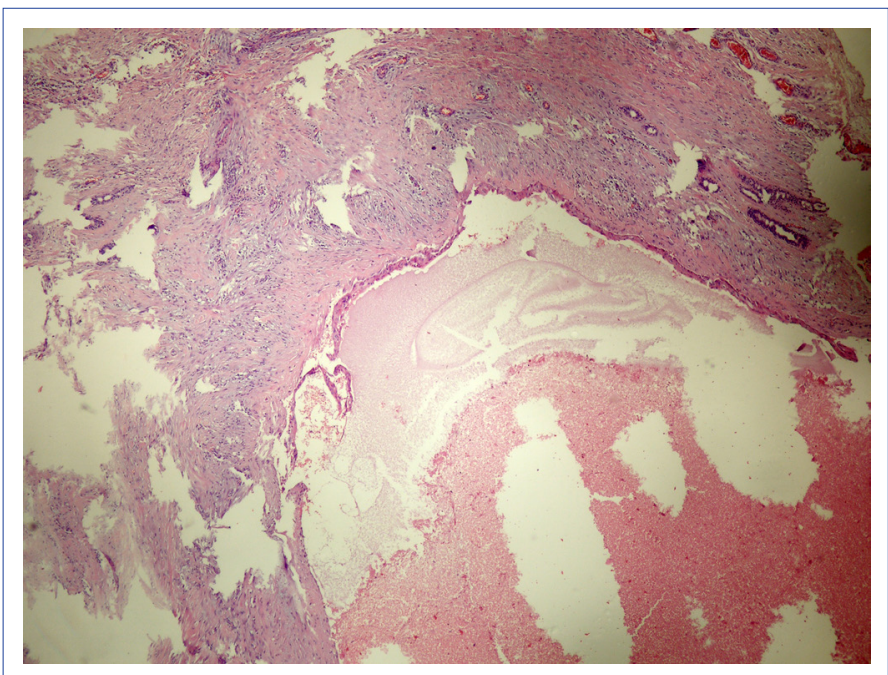

Figure 4. Histopathologic slide of low-grade mucoepidermoid carcinoma of the right parotid gland (magnification, $\times 200$; hematoxylin-eosin stain). 
left neck dissection specimen revealed nonmetastatic lymphadenopathies. Further therapy was not considered due to tumor-free surgical margins and negative cervical lymph nodes. At the 3-year follow-up, the patient's postoperative course was uneventful without evidence of recurrence and metastasis.

\section{Discussion}

Bilateral malignant salivary tumors of the parotid glands may be synchronous or metachronous. ${ }^{[7]}$ Synchronous tumors are defined as separate but simultaneous neoplasms and usually have a tendency of the same histologic type. ${ }^{[6]}$ Whartin's tumor, pleomorphic adenoma, acinic cell carcinoma, adenocarcinoma, and myoepithelial carcinoma are among the previously reported bilateral synchronous tumors of the parotid gland. ${ }^{[6,8]}$ The most common histopathologic type is acinic cell carcinoma, which accounts for six previously reported cases. ${ }^{[9-15]}$ Two cases of adenocarcinoma have been reported. ${ }^{[16,17]}$ Bilateral synchronous mucoepidermoid carcinoma of the parotid gland is extremely rare; only two cases have been reported previously. ${ }^{[1,6]}$ Metachronous bilateral mucoepidermoid carcinoma of the parotid gland is also rare, and only two cases have been reported previously. ${ }^{[3,4]}$

US provides bilateral evaluation of the parotid gland and contributes to the diagnosis of bilateral parotid masses. US and FNAB contribute to the diagnostic work-up of parotid neoplasms. ${ }^{[18]}$ The malignancy detection rate of ultrasound-guided FNAB for parotid tumors is remarkable, whereas its diagnostic accuracy in tumor typing and grading is low. ${ }^{[19,20]}$ Intraoperative frozen sections have been reported to be superior in tumor typing and grading in comparison to FNAB.$^{[19,20]}$ In the present case, FNAB clarified the left parotid mass as mucoepidermoid carcinoma but was inconclusive for the diagnosis of the right parotid mass.

The histological grade is considered as the most important factor in determining the management and predicting the outcome in mucoepidermoid carcinoma of the parotid gland. ${ }^{[21,22]}$ Mucoepidermoid carcinomas are histopathologically classified as low-, intermediate-, and high-grade. Low-grade mucoepidermoid carcinomas usually mimic benign tumors but still have the potential of local invasion and distant metastasis. The cystic component less than 20 $\%$, neural invasion, necrosis, anaplasia, and intense mitotic activity are the histopathologic features that characterize high-grade tumors. High-grade mucoepidermoid carcinomas are associated with increase in locoregional invasion and metastasis rates. In a previous study, the 5-year disease-specific survival rates for low-, intermediate-, and high-grade mucoepidermoid carcinoma among 2.400 pa- tients were reported as $98.8 \%, 97.4 \%$, and $67.0 \%$, respectively. ${ }^{[21]}$

The histological grade of a tumor may not be clearly defined using intraoperative frozen sections in all cases. In the present case, the intraoperative frozen section confirmed mucoepidermoid carcinoma in the left parotid gland but was inconclusive for the tumor grade. However, the intraoperative frozen section was conclusive for typing and grading of the right parotid mass.

Superficial parotidectomy is performed for treating lowgrade mucoepidermoid carcinoma of the superficial lobe of the parotid gland. ${ }^{[23]}$ The suggested management for intermediate-grade mucoepidermoid carcinoma is excision of the lesion with negative surgical margins using total parotidectomy with preservation of the facial nerve. Selective neck dissection in NO patients is recommended both for intermediate- and high-grade mucoepidermoid carcinomas. ${ }^{[23]}$ In the present case, the management of intermediate-grade mucoepidermoid carcinoma in the left parotid gland was accomplished with total parotidectomy along with lateral neck dissection, whereas that of low-grade mucoepidermoid carcinoma in the right parotid gland was accomplished with superficial parotidectomy.

\section{Conclusion}

The diagnosis of malignant tumors of the parotid gland warrants a detailed examination. US is the first choice in imaging modalities. MRI and/or computerized tomography are suggested to determine the expanse of malignant tumors or the presence of metastatic lymph nodes. The radiographic images should be carefully analyzed to identify the possible occult synchronous tumors in the contralateral parotid gland and other salivary glands. FNAB and intraoperative frozen sections contribute to tumor typing and grading for the establishment of a surgical plan. Surgical removal is recommended for the management of synchronous bilateral parotid mucoepidermoid carcinoma, as likewise for all benign and malignant tumors of the salivary glands. A close clinical follow-up is also suggested for the risk of future occurrence or recurrences of metachronous tumors.

\section{Disclosures}

Informed consent: Written informed consent was obtained from the patient for the publication of the case report and the accompanying images.

Acknowledgement: We are deeply grateful to Dr. Tulay Basak (pathologist) for conducting the histopathological examination of the specimens and providing the microscopic images. 
Peer-review: Externally peer-reviewed.

Conflict of Interest: None declared.

Authorship contributions: Concept - M.A., Ö.Ü.; Design - M.A., Ö.Ü.; Materials - M.A., Ö.Ü., F.T., M.Ç.; Data collection \&/or processing - M.Ç., F.T., M.A., Ö.Ü.; Analysis and/or interpretation - M.Ç., F.T.; Literature search - M.A., Ö.Ü., B.U.C.; Writing - M.A.; Critical review - B.U.C.

\section{References}

1. Baid M, Chaturvedi V, Jha J. Bilateral mucoepidermoid carcinoma of parotid. El Med J 2014;2:131-3.

2. Cornog JL, Gray SR. Surgical and clinical pathology of salivary gland tumors. In: Rankow RM, Polayes IM, editors. Disease of the Salivary Glands. Philadelphia: WB Saunders; 1976. p. 99-142.

3. Seifert G. Bilateral mucoepidermoid carcinomas arising in bilateral pre-existing Warthin's tumours of the parotid gland. Oral Oncol 1997;33:284-7.

4. Muthusami JC, Gaikwad P, Raj JP, Abraham DT, Thomas M, Cornerstone V. Metachronous bilateral mucoepidermoid carcinoma of the parotid gland. Indian J Otolaryngol Head Neck Surg 2008;60:245-7.

5. Turnbull AD, Frazell EL. Multiple tumors of the major salivary glands. Am J Surg 1969;118:787-9.

6. Hakuba N, Hyodo M. Synchronous bilateral mucoepidermoid carcinoma of the parotid gland. J Laryngol Otol 2003;117:419-21.

7. Yu GY, Ma DQ, Zhang Y, Peng X, Cai ZG, Gao Y, et al. Multiple primary tumours of the parotid gland. Int J Oral Maxillofac Surg 2004;33:531-4.

8. van Tongeren J, Creytens DH, Meulemans EV, de Bondt RB, de Jong J, Manni JJ. Synchronous bilateral epithelial-myoepithelial carcinoma of the parotid gland: case report and review of the literature. Eur Arch Otorhinolaryngol 2009;266:1495-500.

9. Bauer WH, Bauer JD. Classification of glandular tumors of salivary glands; study of one-hundred forty-three cases. AMA Arch Pathol 1953;55:328-46.

10. Diamani H, Enroth CM, Gerjot T. Bilateral tumors of the parotid gland. J Laryngol Otol 1961;75:699-702.

11. Eneroth CM. Histological And Clinical Aspects Of Parotid Tumours. Acta Otolaryngol Suppl 1964;188:Suppl 191:1-99.

12. Clarke JS, Hentz EC, Mahoney WD. Bilateral acinic cell carcinoma of the parotid gland. Ann Surg 1969;170:866-9.

13. Levin JM, Robinson DW, Lin F. Acinic cell carcinoma: collective review, including bilateral cases. Arch Surg 1975;110:64-8.

14. Nelson DW, Nichols RD, Fine G. Bilateral acinous cell tumors of the parotid gland. Laryngoscope 1978;88:1935-41.

15. Di Palma S, Corletto V, Lavarino C, Birindelli S, Pilotti S. Unilateral aneuploid dedifferentiated acinic cell carcinoma associated with bilateral-low grade diploid acinic cell carcinoma of the parotid gland. Virchows Arch 1999;434:361-5.

16. Berkley WT. Nevus sebaceous complicated by bilateral salivary gland adenocarcinoma. Plast Reconstr Surg Transplant Bull 1959;23:55-63.

17. Ferlito A. Bilateral synchronous trabecular adenocarcinoma of the parotid gland. ORL J Otorhinolaryngol Relat Spec 1978;40:120-6.

18. Henrys CE, Grigg R. Use of fine-needle aspiration cytology in the diagnosis of parotid neoplasms. ANZ J Surg 2015;85:838-42.

19. Zbären P, Nuyens M, Loosli H, Stauffer E. Diagnostic accuracy of fine-needle aspiration cytology and frozen section in primary parotid carcinoma. Cancer 2004;100:1876-83.

20. Nishikawa S, Kawata R, Higashino M, Lee K, Terada T, Kurisu Y, et al. Assessing the histological type and grade of primary parotid carcinoma by fine-needle aspiration and frozen section. Auris Nasus Larynx 2015;42:463-8.

21. Chen MM, Roman SA, Sosa JA, Judson BL. Histologic grade as prognostic indicator for mucoepidermoid carcinoma: a population-level analysis of 2400 patients. Head Neck 2014;36:158-63.

22. Ghosh-Laskar S, Murthy V, Wadasadawala T, Agarwal J, Budrukkar A, Patil N, et al. Mucoepidermoid carcinoma of the parotid gland: factors affecting outcome. Head Neck 2011;33:497-503.

23. Aro K, Leivo I, Mäkitie AA. Management and outcome of patients with mucoepidermoid carcinoma of major salivary gland origin: a single institution's 30-year experience. Laryngoscope 2008;118:258-62. 